\title{
Sexismo, misoginia e LGBTQfobia: desafios para promover o trabalho inclusivo no Brasil
}

\author{
I ${ }^{1}$ Pedro Afonso Cortez, ${ }^{2}$ Marcus Vinícius Rodrigues de Souza, ${ }^{3}$ Ana Paula Salvador, \\ ${ }^{4}$ Luís Fernando Adas Oliveira I
}

Resumo: As práticas de violência permeiam diferentes contextos sociais, perpassando inclusive os espaços laborais. Nesse sentido, é fundamental promover o trabalho inclusivo, pois as práticas de dominação no trabalho relegam à marginalização diferentes atores sociais, incluindo mulheres e LGBTQs, ocasionando prejuízo à saúde psicossocial desses grupos. Com o intuito de contribuir nesse aspecto, propôs-se uma revisão crítica das produções sobre práticas de violência e dominação no contexto de trabalho voltado à população feminina e LGBTQs, a fim de identificar os desafios na proposição de trabalho inclusivo no Brasil. Foram empregados os descritores "trabalho" e "preconceito" ou "discriminaçáo" em uma varredura da literatura entre 1995 e 2017 na base de dados Scielo, a qual permitiu a identificaçâo de 54 estudos inclusos na presente revisão. Os resultados apontados pelos estudos revisados constataram violência com mulheres e LGBTQs nos diversos contextos laborais, praticada por chefes, colegas, clientes, entre outros sujeitos. Assim, apresenta-se como desafio para a proposição do trabalho inclusivo a implementação de intervençōes educativas e assistenciais, respaldadas por legislaçóes e políticas públicas que promovam o respeito e a equidade ao diverso como tônica nas organizações sociais e nos contextos de trabalho brasileiros.

> Palavras-chave: discriminação no trabalho; trabalho feminino; homofobia; identidade de gênero; ação afirmativa.

\author{
1 Programa de Pós-Graduação \\ em Psicologia, Universidade São \\ Francisco. Campinas-SP, Brasil \\ (cor.afonso@gmail.com). \\ ORCID: 0000-0003-0107-2033. \\ 2 Hospital das Clínicas, \\ Universidade Federal de Minas \\ Gerais. Belo Horizonte-MG, \\ Brasil (marcusrodriguessouza@ \\ hotmail.com). \\ ORCID: 0000-0003-1550-1222. \\ ${ }^{3}$ Programa de Pós-Graduação \\ em Psicologia, Universidade São \\ Francisco. Campinas-SP, Brasil \\ (salvador.anapaula@outlook.com). \\ ORCID: 0000-0001-5277-1657. \\ ${ }^{4}$ Programa de Pós-Graduação \\ em Análise do Discurso \\ Político e Jurídico, Faculdade \\ de Administração, Ciências, \\ Educação e Letras. Curitiba-PR, \\ Brasil (adas534@gmail.com). \\ ORCID: 0000-0002-6310-4873.
}

Recebido em: 14/02/2019 Revisado em: 09/05/2019 Aprovado em: 06/06/2019 


\section{Introdução}

Em nosso contexto de época, as relaçôes de poder e dominação tendem a negar as diferenças identitárias, relegando à margem alguns sujeitos. Destacam-se entre eles mulheres e LGBTQs — Lésbicas, Gays, Bissexuais, Transgêneros e Queers —, que sofrem de forma recorrente como alvo de práticas de dominação e violência. Em estudo exploratório sobre o tema, cerca de 40\% de LGBTQs relataram serem alvos de violência no trabalho (PEREIRA; COSTA, 2016), incidente também sobre as mulheres cisgênero (NICOLSON, 2015) e transgênero (WINTER et al., 2016). Em razão dessas práticas, mulheres e LGBTQs tendem a apresentar maior nível de estresse e sofrimento no trabalho, o que torna fundamental ensaiar contribuiçôes que visem à promoção do trabalho inclusivo e à extinção de práticas de dominação em ambientes laborais (KELLEHER, 2009).

Entre as práticas de dominação empregadas nos grupos minoritários, identificamse o preconceito (atitude desfavorável em relação a determinados grupos sociais) e a discriminação (comportamentos e verbalizaçôes de violência e/ou ódio direcionadas a grupos específicos), que resultam na segregação social - fronteira instituída no campo simbólico-material que relega à marginalização determinados grupos (SANTOS, 2017). No presente manuscrito, optou-se por abarcá-las conjuntamente como práticas de violência e dominação, devido à polissemia encontrada nos estudos analisados ao longo da corrente investigação, que inviabilizou a exploração delas por meio de significantes distintos.

Frente às mulheres, as práticas de dominação geralmente pautam-se no sexismo e acontecem baseadas principalmente na falácia da supremacia biológica masculina. Discursos eugenistas e clássicos filosóficos preconizaram durantes séculos o homem cis, hétero e branco como ideal biológico e social, dotando-o de representaçôes universais associadas ao ideal perfeito e proximidade ao sagrado (OTINIANOVERISSIMO, 2014). O feminino, por sua vez, seria apreendido como incompleto, imperfeito e disposto à suposta serventia ao corpo masculino dominante, o que favoreceu a ocorrência de práticas institucionais violentas frente ao feminino ao longo do desenvolvimento das sociedades (VERNIERS; VALA, 2018). No caso dos LGBTQs, as práticas discriminatórias fundamentam-se na LGBTQfobia, as quais são definidas como ações violentas direcionadas ao diverso que acontecem pelo potencial risco que a diversidade propóe ao ideário machista, o qual necessita 
da ordenação de identidades binárias para a manutenção do padrão masculino hegemônico (IBRAHIM, 2016).

Destaca-se a ocorrência dessas práticas nos contextos laborais, pois o trabalho se apresenta como atividade recorrente e difusa na coletividade. Assim, contextos laborais violentos e outras condiçôes contextuais negativas resultam em grave dano à efetivação do potencial dos sujeitos que sofrem com a violência nesses espaços, dado que o trabalho é central na vida de grande parte da coletividade (CORTEZ; ZERBINI; VEIGA, 2019a). Ademais, por se apresentarem difusas por todo o espaço coletivo, é crucial analisar as práticas violentas na organização social do trabalho em diferentes instâncias, uma vez que se iniciam desde o processo seletivo para ingressar no cargo, incidindo até o topo das organizaçóes por meio de políticas e práticas laborais que prejudicam mulheres e LGBTQs (THOMSON; GRANDY, 2018).

A visibilidade de outras ordenaçóes, como a feminina e a LGBTQ, que questionam o padrão heteronormativo, colocam em xeque a suposta exclusividade, perfeição e completude do ideário masculino sexista, levando à ocorrência de práticas de dominação frente ao diverso como estratégia perversa utilizada na manutenção do ordenamento masculino dominante (WOULFE; GOODMAN, 2018). Isso resulta em diferenças em recompensas salariais, promoçóes e benefícios, entre outras dinâmicas que privilegiam o masculino e o padrão de identidade binária às custas do bem-estar, oportunidade e saúde psicossocial dos grupos minoritários (SILVA; FRANÇA; PINHO, 2016).

Em síntese, mulheres e LGBTQs são relegados à invisibilidade social por práticas de dominação e violência, o que torna emergente a importância de tratar o tema de inclusão no trabalho visando a esses públicos, dado que a manutenção do ordenamento desigual entre gêneros impacta negativamente na saúde das coletividades nos espaços laborais (GÖÇMEN; YILMAZ, 2017; LLOREN; PARINI, 2017). Tendo isso em vista, a presente investigação visou contribuir com a questão, propondo os seguintes objetivos:

1) revisar a literatura brasileira sobre práticas de dominação e violência frente às mulheres e aos LGBTQs;

2) realizar uma análise crítica das evidências propostas por meio dessas produçóes, com o intuito visibilizar os desafios que se apresentam à promoção do trabalho inclusivo nos espaços laborais brasileiros. 


\section{Método}

Optou-se por analisar as contribuições estabelecidas em artigos científicos com disponibilidade de acesso em dados abertos (open access). Elegeram-se os artigos científicos pelo interesse de produçóes técnico-científicas no tema. A opção por produçôes open access aconteceu por estas se apresentarem como as principais disseminadoras das comunicaçóes textuais científicas atualmente. A base de dados selecionada para resgatar os artigos foi a Scielo (Scientific Electronic Library Online). A opção por essa base ocorreu por identificá-la como aquela com maior abrangência de estudos brasileiros em open access nas áreas de Ciências Humanas, Sociais Aplicadas e da Saúde. Em linhas gerais, foram adotados os procedimentos de revisão integrativa de literatura, cujo foco é mapear de forma qualitativa, processual e descritiva um determinado campo de investigação (WHITTEMORE; KNAFL, 2005).

Salienta-se que não houve delimitação temporal a priori, com o intuito de maximizar a abrangência e representatividade temporal dos estudos identificados. Os descritores empregados para localizar os artigos foram selecionados por meio do Dicionário Eletrônico de Descritores em Ciências da Saúde (DeCS - http://decs.bus. $b r /$ ), disponíveis em língua portuguesa, devido ao foco na literatura brasileira, a qual se mostra predominantemente divulgada em português. Os termos discriminação, preconceito, trabalho e segregação foram, então, aplicados de forma conjunta e separada para busca no Scielo até a obtenção do operador com maior abrangência do estado da literatura. O operador final para a busca com maior abrangência incluiu a sintaxe booleana ("trabalho" AND ("preconceito" OR "discriminação")).

Foi possível resgatar por meio dessa sintaxe 578 produçóes datadas entre 1995 e 2017. Com isso, realizou-se a leitura dos títulos e resumos, resultando na exclusão de 440 artigos sem relação com a temática da revisão, uma vez que abrangiam “discriminação" como processo biológico, físico-químico (ARRUDA et al., 2011) e, portanto, fora da acepção de práticas de dominação e violência proposta no escopo deste estudo e das Ciências Humanas, Sociais Aplicadas e da Saúde. Isso resultou na manutenção de 138 trabalhos com temática adequada à revisão, que foram lidos na íntegra. Destes, 84 foram excluídos por não tratarem de práticas de dominação e violência frente às mulheres e LGBTQs, o que gerou um total de 54 artigos inclusos na presente revisão. 
Pautando-se na concepção de que a organização social é construída, uma vez que as ideias e valores dominantes são elaborados e compartilhados ao longo da interação entre diferentes atores sociais (BORGES et al., 2016), optou-se pela utilização de referencial analítico indutivo. Especificamente, aplicou-se a grounded theory, cuja predominância descritiva possibilita conjugar as evidências expostas nos estudos para gerar inferências sobre o fenômeno analisado (STRAUSS; CORBIN, 1994). Ainda nessa perspectiva, os procedimentos empregados para o levantamento dos estudos foram replicados de forma independente para verificar a consistência frente ao referencial empregado (HOLLOWAY; TODRES, 2003).

Desta forma, dois pesquisadores externos replicaram o procedimento de localização e seleção dos textos, obtendo concordância de $98 \%$ com o processo empregado pelos autores. Ademais, para sintetizar os estudos em categorias, foi empregada a análise de conteúdo (HSIEH; SHANNON, 2005), a qual também foi replicada de forma independente por pesquisadores externos, alcançando-se $92 \%$ de concordância frente às categorias geradas pelos autores. Por fim, ressalta-se que, nos casos em que as classificaçôes se mostraram divergentes, optou-se por incluir a versão com maior abrangência em relação aos trabalhos encontrados na revisão, a fim de maximizar a efetividade do estudo frente ao conteúdo informacional proposto pela literatura.

\section{Resultados}

\section{Produção do conhecimento entre diferentes áreas do conhecimento}

Houve predominância do método qualitativo entre os trabalhos identificados. Nesses estudos, o uso de entrevistas e aportes monográficos se mostrou como a metodologia dominante. A opção pelo método quantitativo também foi razoável nas investigações presentes na revisão. Como metodologia, os estudos quantitativos priorizaram técnicas estatísticas descritivas e inferenciais, visando principalmente a comparar a diferença salarial entre gêneros. De forma minoritária, aplicaram-se métodos mistos e teóricos, abrangendo o uso integrado de questionários, observaçôes, grupos, dentre outros recursos, e a análise de outras produçôes textuais tratando a diversidade no trabalho e temas relacionados. Na tabela 1 apresentou-se uma síntese dos elementos bibliométricos das produçóes inclusas na revisão. 
Tabela 1. Descrição dos elementos bibliométricos dos estudos

\begin{tabular}{|c|c|c|c|c|c|}
\hline Método & & Metodologias & & Áreas do conhecimento & \\
\hline Qualitativo & 33 & Entrevistas & 24 & Administração & 11 \\
\hline Quantitativo & 14 & Técnicas estatísticas & 13 & Ciências Sociais & 9 \\
\hline Teórico & 2 & Monográficas & 10 & Economia & 8 \\
\hline \multirow[t]{7}{*}{ Mistos } & 5 & Observação participante & 1 & Saúde Coletiva & 7 \\
\hline & & Questionário & 1 & Enfermagem & 6 \\
\hline & & Técnicas mistas & 5 & Psicologia & 5 \\
\hline & & (questionário, grupos & & Demografia & 3 \\
\hline & & observação e/ou estatísticas) & & Direito & 2 \\
\hline & & & & Educação & 2 \\
\hline & & & & Interdisciplinar & 1 \\
\hline
\end{tabular}

Fonte: elaboração própria.

Verificou-se ainda, em relação à área de conhecimento predominante entre os autores, elevada contribuição da Administração, por meio de estudos de práticas organizativas e violentas nos espaços de trabalho. As Ciências Sociais, abrangendo práticas relativas à assistência social e análises dos determinantes sociais da violência e dominação, também demonstraram elevada contribuição entre os estudos revisados (SANTOS, 2016). A contribuição da Economia aconteceu principalmente pela análise dos fatores influenciadores das diferenças salariais com o uso de métodos estatísticos de decomposição para identificar variáveis relevantes a fim de apreender as práticas de dominação (CACCIAMALI; HIRATA, 2005; CAMBOTA; PONTES, 2007; GIUBERT; MENEZES, 2005). As elaboraçôes da Saúde Coletiva e Enfermagem apontaram para a existência de relaçôes socioprofissionais assediadoras no contexto laboral de saúde, bem como indicaram aspectos relativos à saúde que maximizam o estigma e a exclusão social de subgrupos específicos, como é o caso de sujeitos que vivem com HIV/AIDS (FREITAS et al., 2012).

Pelas contribuiçóes da Psicologia, apreendeu-se o sofrimento psíquico que açóes de violência e dominação social promovem nos sujeitos, bem como evidenciou-se de que forma as crenças influenciam, numa perspectiva psicossocial, na instauração das diferenças e práticas de dominação como ação social (FLEURY; TORRES, 
2007). Os estudos da Demografia analisaram principalmente os dados da PNAD (Pesquisa Nacional por Amostra de Domicílios) segmentando como perfil populacional com maior marginalização nos espaços de trabalho mulheres com baixa escolaridade, etnia negra ou parda, inscritas em territórios marginalizados e com predominância de ocupaçóes voltadas ao cuidado, ao trabalho doméstico ou a outras ocupaçóes perpassadas por vínculos trabalhistas informais (BIDERMAN; GUIMARÃES, 2004; FRANCO; DRUCK; SELIGMANN-SILVA, 2010; MARRI; WANJMAN, 2007).

Os autores do Direito indicaram a ausência de políticas e legislaçóes sobre o tema, assim como evidenciaram o tensionamento entre liberdade de discurso e práticas de dominação, salientando como ponto de interdição do discurso pelo uso da força estatal o momento em que a potência discursiva se prepara para o ato que viola a dignidade humana (SMITH; SANTOS, 2017). Por fim, os pesquisadores da Educação e Interdisciplinaridades contribuíram com a proposição de uma agenda educativa libertadora, capaz de expandir as concepçóes de profissão e mundo do trabalho para o diverso, em vez da limitação binária, em favor de um espaço dialógico e inclusivo nas instituiçóes educativas e demais instâncias sociais (FONSECA, 1995).

\section{Práticas de violência e dominaçáo no trabalho predominantes frente às mulheres e LGBTQs}

Ao se considerar as mulheres como alvo, a principal prática violenta no trabalho indicada pelos estudos refere-se às menores remunerações e oportunidades de ascensão profissional (CLOSS; OLIVEIRA, 2015; MADALOZZO, 2010; ORRILLO; LOUREIRO, 2004; JACINTO, 2005; SILVA; FRANÇA; PINHO, 2016). Outra forma bastante elencada foi o assédio, abrangendo diferentes facetas como o assédio moral, sexual e implícito, o qual se manifesta principalmente por meio de piadas (HIGA, 2016). A questão étnica também se apresentou no mundo do trabalho, potencializando a exclusão de mulheres negras e pardas (FERNANDES, 2015; GUIMARÁES, 2002; OLINTO; OLINTO, 2000). No aspecto ocupacional, as mulheres trabalhadoras informais, prostitutas, catadoras de material reciclável, domésticas e cuidadoras foram retratadas como aquelas em que as práticas de dominação acontecem em maior grau (COELHO et al., 2016; SILVA; CAPPELLE, 2015).

Numa perspectiva econômica, a limitação ao crédito e financiamento para mulheres que buscavam empreender também foi ressaltada (CARVALHO; 
TANURE; ANDRADE, 2010; JONATHAN, 2005). Outra prática de dominação destacada foi a estigmatização e exclusão nos contextos laborais de mulheres deficientes e que vivem com HIV/AIDS (CECHIM; SELLI, 2007; FERREIRA; FIGUEIREDO; SOUZA, 2011). No âmbito institucional, as organizaçôes foram designadas como machistas e sexistas, priorizando ideais masculinos e excluindo as mulheres (CASTELAR et al., 2015). Também nessas organizaçōes foi ressaltado o esteticismo como uma prática violenta por inserir nas instituições a exigência de uma imagem feminina estereotipada com o uso de maquiagens e adereços, como requisito para execução das atividades laborais pelas mulheres (LIVRAMENTO; HOR-MEYLL; PESSÔA, 2013). Na tabela 2, essas práticas foram apresentadas.

Tabela 2. Descriçấo das práticas de dominação e violência elencadas nos estudos

\begin{tabular}{|c|c|c|}
\hline Grupo-alvo & Práticas & Frequência \\
\hline \multirow{8}{*}{ Mulheres } & $\begin{array}{l}\text { Salarial e profissional (menor remuneração e oportunidades de } \\
\text { ascensão na carreira) }\end{array}$ & 16 \\
\hline & Assédio (moral, sexual e implícito por meio de chistes) & 8 \\
\hline & Étnica (negras e pardas) & 5 \\
\hline & $\begin{array}{l}\text { Ocupacional (catadoras, prostitutas, trabalhadoras informais, } \\
\text { cuidadoras e domésticas) }\end{array}$ & 4 \\
\hline & $\begin{array}{l}\text { Econômica (dificuldade de acesso a empréstimos e ausência de } \\
\text { incentivos para empreender) }\end{array}$ & 4 \\
\hline & Estigma social (deficiências e outros aspectos como HIV/AIDS) & 3 \\
\hline & Institucional (priorizar valores e educação sexistas) & 2 \\
\hline & Estética (exigir padróes de beleza estereotipados) & 1 \\
\hline \multirow{4}{*}{ LGBTQs } & Violência (agressão física e assédio implícito por meio de chistes) & 6 \\
\hline & $\begin{array}{l}\text { Estigma social (patologizar a diversidade identitária e outros } \\
\text { aspectos como HIV/AIDS) }\end{array}$ & 4 \\
\hline & $\begin{array}{l}\text { Institucional (legitimar LGBTQfobia e excluir diversidade da } \\
\text { organização) }\end{array}$ & 3 \\
\hline & $\begin{array}{l}\text { Transfobia (ignorar a identidade social declarada pelo sujeito e } \\
\text { excluir afeminados) }\end{array}$ & 2 \\
\hline
\end{tabular}

Fonte: elaboração própria. 
Em relação às práticas violentas evidenciadas nos estudos frente aos LGBTQs, verificou-se a violência, por meio de agressão física e assédio implícito com piadas, como a prática predominante (IRIGARAY; SARAIVA; CARRIERI, 2010). Outro aspecto indicado foi o estigma social que se fez presente por tentativas de classificar como desviantes ou patológicas as identidades diversificadas, o que também aconteceu com os sujeitos que vivem com HIV/AIDS (SOUSA; FERREIRA; SÁ, 2013). Na seara institucional, a omissão das organizaçôes frente às ações violentas, permitindo legitimar a LGBTQfobia como prática recorrente e, consequentemente, a exclusão da diversidade dos espaços de trabalho, fez-se presente (SIQUEIRA, 2009). Por fim, os estudos que salientaram a transfobia indicaram que entre LGBTQs as identidades que fazem a transição do corpo biológico para compatibilizá-lo com a identidade social apresentam-se ainda mais alvejadas pelo estigma e pelas práticas violentas no trabalho (CHIES, 2010; SMITH; SANTOS, 2017).

\section{Percepção de práticas de violência e dominação em contextos laborais}

Nos estudos revisados as mulheres percebiam predominância de atos violentos por supervisores com hierarquia superior, colegas de trabalho, omissão estatal, seguidos de engenheiros e trabalhadores da construção civil e professores universitários (LOMBARDI, 2017; MOSCHKOVICH; ALMEIDA, 2015; SILVA; RIBEIRO, 2014; PAUTASSI, 2007). Também foram elencados como praticantes desses atos policiais militares e clientes (BEZERRA; MINAYO; CONSTANTINO, 2013). No caso de trabalhadoras da área da saúde, os médicos foram destacados. Outros sujeitos percebidos como atores de atos violentos foram diretores escolares, investidores, publicitários e outras mulheres (GONTIJO; MELO, 2017; MIRANDA; MAIA, 2017). No caso de outras mulheres, as práticas de dominação aconteciam pela manifestação de mulheres supostamente empoderadas frente a mulheres que trabalhavam em contextos voltados ao cuidado e às atribuiçôes domésticas (MOLINIER, 2014). A relação de atores de práticas de dominação e os contextos laborais percebidos por cada grupo e relatado nos estudos revisados é sintetizada na tabela 3 . 
Tabela 3. Percepçôes de atores sociais de práticas violentas e de dominação nos estudos

\begin{tabular}{|c|c|c|c|c|c|c|c|}
\hline \multicolumn{4}{|c|}{ Mulheres } & \multicolumn{4}{|c|}{ LGBTQs } \\
\hline Atores & Frequência & $\begin{array}{l}\text { Contextos } \\
\text { laborais }\end{array}$ & Frequência & Atores & Frequência & $\begin{array}{c}\text { Contextos } \\
\text { laborais }\end{array}$ & Frequência \\
\hline Supervisores & 15 & $\begin{array}{c}\text { Empresarial } \\
\text { privado }\end{array}$ & 21 & $\begin{array}{c}\text { Colegas de } \\
\text { trabalho }\end{array}$ & 6 & $\begin{array}{c}\text { Empresarial } \\
\text { privado }\end{array}$ & 9 \\
\hline $\begin{array}{c}\text { Colegas } \\
\text { de trabalho }\end{array}$ & 13 & Universitário & 3 & Supervisores & 4 & Hospitalar & 3 \\
\hline Estado & 4 & $\begin{array}{l}\text { Informais e } \\
\text { precários }\end{array}$ & 4 & $\begin{array}{l}\text { Policiais } \\
\text { militares }\end{array}$ & 2 & $\begin{array}{c}\text { Boates } \\
\text { LGBTQs }\end{array}$ & 2 \\
\hline $\begin{array}{l}\text { Engenheiros, } \\
\text { construtores }\end{array}$ & 4 & $\begin{array}{c}\text { Canteiros de } \\
\text { obras }\end{array}$ & 2 & $\begin{array}{c}\text { Outros } \\
\text { LGBTQs }\end{array}$ & 2 & $\begin{array}{l}\text { Judiciais e } \\
\text { policiais }\end{array}$ & 2 \\
\hline $\begin{array}{c}\text { Professor } \\
\text { universitário }\end{array}$ & 3 & $\begin{array}{l}\text { Policiais e } \\
\text { militares }\end{array}$ & 2 & Médicos & 2 & Bancário & 1 \\
\hline $\begin{array}{l}\text { Policiais } \\
\text { militares }\end{array}$ & 2 & $\begin{array}{l}\text { Boates de } \\
\text { prostituiçăo }\end{array}$ & 1 & Estado & 2 & & \\
\hline Clientes & 2 & Hospitalar & 1 & Enfermeiras & 1 & & \\
\hline Médicos & 2 & $\begin{array}{l}\text { Industrial } \\
\text { privado }\end{array}$ & 1 & Clientes & 1 & & \\
\hline $\begin{array}{l}\text { Diretores } \\
\text { escolares }\end{array}$ & 1 & Ensino básico & 1 & & & & \\
\hline Investidores & 1 & Bancário & 1 & & & & \\
\hline Publicitários & 1 & Jornalístico & 1 & & & & \\
\hline $\begin{array}{l}\text { Outras } \\
\text { mulheres }\end{array}$ & 1 & $\begin{array}{l}\text { Clínicas de } \\
\text { idosos }\end{array}$ & 1 & & & & \\
\hline
\end{tabular}

Fonte: elaboração própria.

Considerando-se a percepção dos LGBTQs, houve predominância de atos violentos partindo dos colegas de trabalho e supervisores hierárquicos. Os policiais militares também foram indicados como autores de práticas de dominação. Outros LGBTQs foram percebidos como autores de práticas violentas frente a identidades que se apresentavam mais afeminadas (IRIGARAY; FREITAS, 2011; SOUZA; PEREIRA, 2013). Nos contextos laborais de saúde, médicos e enfermeiras foram apontados como atores de atos violentos de forma implícita frente a LGBTQs (JESUS et al., 2010; SANTOS; TAKAHASHI, 2000). O Estado foi ressaltado por meio da omissão de ações fiscalizatórias e inclusivas, bem como os clientes também foram 
apreendidos como responsáveis por violentar LGBTQs nos espaços de trabalho (WINTHER; GOLGHER, 2010).

Em síntese, verificou-se que tanto no caso de LGBTQs quanto frente às mulheres as práticas de dominação e violência são exercidas nos diferentes espaços de trabalho. A violência ocorre por sujeitos que se situam dentro da organização (colegas e chefias) e por aqueles que se apresentam no espaço de trabalho de forma transitória, tais como clientes e policiais (BRAZ, 2015). Para os dois grupos, a omissão estatal é relevante, o que pode explicar as razões das práticas de dominação e violência se generalizarem em diferentes espaços laborais, que vão desde empresas do setor privado até hospitais, bancos e outros dispositivos e organizaçóes como aquelas das esferas policiais, militares e judiciais (GARCIA; SOUZA, 2010).

\section{Discussão}

Pelas diferentes contribuiçóes prestadas pelos estudos supracitados, nota-se que as formulaçôes propostas nos estudos revisados incidem sobre o ponto central para a proposição do trabalho inclusivo: as práticas de violência e dominação frente às mulheres e LGBTQs são generalizadas e perpassam os múltiplos espaços sociais. Para superar essa questão, ensaiam-se contribuiçôes por meio do panorama descrito nos estudos revisados. Efetivar a promoção da inclusão nos espaços laborais demanda pela participação social e efetivo exercício cidadão em um Estado Democrático para que legislaçôes de proteção aos Direitos Humanos, políticas assistenciais, educacionais e de saúde associadas ao trabalho sejam desenvolvidas em favor da promoção da inclusão de mulheres e LGBTQs nas organizaçōes laborais (PAUTASSI, 2007). Considerando-se a amplitude dessas práticas em diferentes instâncias sociais, sugerese que a elaboração de políticas e legislaçôes visando a contribuir com o tema deva emergir por meio de um princípio integrativo, cujo foco de atenção psicossocial e promoção de saúde atue em três níveis distintos, a saber: 1) ação educacional; 2) orientação profissional; e 3) organizações de trabalho.

$\mathrm{Na}$ esfera educativa, a promoção de educação e orientação profissional libertadora possibilita o surgimento de aspiraçóes e inserções profissionais que não se respaldem em sexismo, propiciando novos padrôes de interação no jogo social (WERMELINGER; MACHADO; AMÂNCIO, 2007), o que é fundamental para a instituição do trabalho inclusivo. A educação libertária rompe com os padrôes 
estigmatizantes frente aos papeis sociais, fazendo com que o ciclo de conflitos ocasionados pelas práticas de dominação e exclusão sejam rompidos. Para isso, é fundamental que nos espaços educacionais seja promovida uma cultura dialógica, não violenta e favorável à paz, com o intuito de valorizar a fluidez e a diversidade como tônica nas açôes de orientação profissional e práticas educativas, capaz de fluir para outros espaços sociais. Nos espaços de educação formal, informal, continuada, seja de nível médio e/ou superior, para a atuação em saúde vislumbra-se a possibilidade de formação de pares capazes de se tornarem agentes multiplicadores dessa realidade nas organizações sociais (CORTEZ; SOUZA, 2017).

No campo de orientaçáo profissional, a fluidez dessa mentalidade educacional libertária possibilita que o padrão excludente dominante em nossa realidade seja transmutado. Com isso, princípios mais equitativos poderão balizar questôes centrais para a difusão do trabalho inclusivo, como a divisão social do trabalho, com o intuito de torná-lo mais inclusivo e equitativo entre diferentes gêneros. Nessa seara, é importante resistir aos apriorísticos de que determinas funçóes, cargos, tarefas, atribuiçôes e níveis hierárquicos são restritos a gêneros ou qualquer outra condição (CORTEZ; ZERBINI; VEIGA, 2019b). Per si, essa concepção possibilita maior inserção da diversidade em posições de liderança, influência social e protagonismo social, o que incide na difusão de valores benéficos aos Direitos Humanos e à diversidade nos diferentes dispositivos sociais, maximizando a inclusão de mulheres e LGBTQs entre carreiras e ocupaçôes anteriormente protagonizadas exclusivamente por homens (MELO, 2004). Ao alcançar o campo educacional e profissional com uma mentalidade inclusiva, libertária e equitativa, atingem-se as organizaçóes de trabalho, as quais passam a ser impactadas pelas minorias que nela podem atuar estrategicamente em favor da mentalidade libertária e do bem-estar social (CORTEZ; VEIGA, 2019).

Nas organizaçóes laborais, o trabalho inclusivo pode se manifestar quando os sujeitos fomentam critérios de práticas, relativas à remuneração e às recompensas, e acesso aos cargos e promoçôes mais equitativos, cujas influências associam-se aos tensionamentos próprios da natureza do trabalho: a) competências para realização das tarefas e b) requisitos profissiográficos dos cargos e funçôes. Qualquer outro suposto requisito pautado em práticas de discriminação e violência é filtrado, de forma que a coletividade define para o dispositivo de trabalho aquelas que, de fato, demonstram relevância para o desempenho da organização. Para tanto, demanda-se 
a participação representativa e equitativa dos diferentes atores sociais na definição dos princípios e práticas a serem propostos nas organizaçóes, com o intuito de maximizar paridades entre homens, mulheres e LGBTQs. Assim, o sexismo e outra práticas de dominação não encontrarão espaço para se manifestar, cedendo espaço às práticas justas, consultivas e inclusivas de gestão, as quais possibilitarão que o trabalho inclusivo se torne a tônica no ambiente de trabalho (TONELI; PERUCCHI, 2006).

Ainda sobre as organizações de trabalho, abrangendo o campo simbólico, fazse mister tornar visível a inclusão, permitindo que a identidade social "saia do armário" e o sujeito possa se afirmar como se percebe, encontrando reconhecimento e aceitação no uso da identidade social no contexto de trabalho. Ademais, com o intuito de manter a inclusão no trabalho como tônica, requer-se a efetivação de canais institucionais capazes de sancionar incitadores ao ódio e encaminhar questóes relativas aos possíveis ataques que o binarismo, a misoginia e a heteronormatividade vierem a estabelecer (CORTEZ; ZERBINI; VEIGA, 2019b) como forma de prevenir condições laborais geradoras de dano e adoecimento à coletividade (CORTEZ et al., 2019). Além disso, entre as ações passíveis de prevenir a recorrência ao ódio em expressões de intolerância, verifica-se a necessidade de desenvolver a sensibilização de colegas e superiores hierárquicos sobre a diversidade, com o intuito de permitir a transição, negociação e colaboração coletiva entre os pares, rumo a melhores condições de vida e trabalho a todos aqueles que constituem o corpo de ação do espaço laboral (SANCHES; GEBRIM, 2003).

Por último, é fundamental destacar que para que as açóes, encadeadas entre práticas educativas, orientação profissional e organizaçóes de trabalho, adquiram maior efetividade na proposição do trabalho inclusivo, demanda-se a elaboração e implementação de políticas públicas e legislaçóes educativas, assistenciais, trabalhistas e de saúde pautadas na busca pela efetivação dos Direitos Humanos e equidade entre os diferentes agentes sociais. Afinal, a ausência de políticas e legislaçôes mantém a rigidez do tecido social, demandando que, anterior a qualquer ato que vislumbre a inclusão no ambiente de trabalho, seja preciso estabelecer estratégias a priori, buscando superar um desafio que perpassa o contexto laboral no Brasil: promover a inclusão e efetiva participação democrática e cidadá dos brasileiros nos dispositivos por meio de controle social (MONTEIRO; CECCHETTO, 2009; PAIXÃO; GOMES, 2008). Disso decorre a importância de se promover práticas permanentes de educação, 
assistência social e efetivação de direitos sociais, pois somente com a consolidação da participação social e, consequentemente, efetividade do controle social no Estado democrático é que a diversidade terá espaço para ressoar nas diferentes instâncias sociais, possibilitando a existência de políticas e práticas de saúde e trabalho cujas fundamentações predominantes sejam a busca pela inclusão social e o fomento da equidade (CORTEZ et al., 2017; SOUZAS; ALVARENGA, 2007).

\section{Considerações finais}

Parece importante reiterar que o maior desafio de se promover o trabalho inclusivo respalda-se na rigidez da própria organização social. Em grande parte, o que inviabiliza mudanças concretas em práticas educativas, orientação profissional e condiçôes de organização do trabalho inclusivo é a atuação em favor do retrocesso exercida por meio de atores sociais que se encontram em posição de protagonismo atualmente. Pelas categorias evidenciadas nos estudos, é possível destacar agentes dos setores governamental, militar, judiciário, acadêmico, construção civil, bancário, educacional e da assistência social como aqueles com importância central ao tratar o tema. Especificamente no que tange ao desenvolvimento de políticas públicas e privadas para fomentar a promoção e o respeito à diversidade em instituições e grupos que atuam nesses setores.

Além disso, ao se considerar a centralidade desses setores na organização social, é possível inferir que em uma sociedade em que as posiçôes estratégicas são ocupadas por sujeitos cuja mentalidade refuta a diversidade e o feminino em favor da exaltação do ideal cis, hétero e branco, as múltiplas formas identitárias não encontram outro espaço senão a marginalidade. Nesse sentido, apresenta-se como elemento crucial a organização social e profissional de grupos para promoção de Direitos Humanos e práticas inclusivas nesses setores como forma de impactar de forma concreta nas esferas supracitadas. Gerar a inclusão nos espaços laborais perpassa por transformar os desafios para inclusão em um campo ativo para atuação cidadã em favor de visibilidade que possibilite ao diverso condição de existência e inserção ativa, o que, per si, requer controle social ativo constante como resistência ao retrocesso e à violência institucional e resistência instituída frente à diversidade.

Reitera-se novamente a importância do controle social e da participação cidadã expandida, pois, além de detalhar a dinâmica de preconceito, discriminação e 
segregação na realidade concreta, também habilita, na população assistida e nas categoriais profissionais socialmente ativas, atuar como agente multiplicador de ideais humanizadores e inclusivos nos diferentes espaços sociais (CORTEZ; SOUZA; OLIVEIRA, 2018). Assim como acontece em outros espaços sociais, esta postura colaborativa e articulada em rede é fundamental para promover o trabalho inclusivo. Afinal, sem a sensibilização e mudança efetiva nos setores que condicionam grande parte da organização social, não será possível vislumbrar espaços laborais favoráveis à inclusão. Em síntese, o trabalho inclusivo perpassa a própria organização e seus atores sociais se movimentam em favor desses ideais nas diferentes esferas e espaços coletivos, os quais resultam na transgeneralização dos princípios que fundamentam a convivência, as trocas e relaçôes da coletividade em condiçôes de equidade e inclusão para os diferentes pares.

À guisa de conclusão, cabe salientar, entre as limitaçôes do presente estudo, a conjugação das práticas de dominação em um único significante, uma vez que diferentes estudos presentes da revisão os trataram como sinônimos. Neste sentido, a distinção entre preconceito, discriminação e segregação social deve ser explorada em estudos futuros, sendo desejável expandir as buscas para outras minorias, grupos específicos da população LGBTQs, diferentes grupos étnicos-raciais, pessoas com deficiência e populaçôes tradicionais. Ademais, a elaboração de investigaçóes empíricas qualitativas e quantitativas, que vislumbrem o impacto de cada uma delas em situaçóes concretas, poderá fornecer insights adicionais às contribuiçôes geradas no presente estudo como alternativa à promoção do trabalho inclusivo.

No campo das práticas relativas à assistência clínica, educacional e psicossocial, encontra-se um espaço profícuo para compreender de forma pormenorizada essas dinâmicas. Ressalta-se, inclusive, a possibilidade de se utilizar o método clínico analítico e interpretativo, para apreender tensionamentos implícitos ao tema, com o intuito de visibilizar as estratégias individuais, coletivas e institucionais condicionantes e resistentes frente às práticas violentas. Compreender essas dinâmicas, despertando o lugar de fala e consciência coletiva dessas minorias, além de promover o fortalecimento desses sujeitos na realidade concreta, incide sobre a condição primeira para promoção do trabalho inclusivo: a humanização e politização dos atores e dispositivos sociais de saúde e trabalho para resistir às investidas e retrocessos propostos por setores e agentes sociais violentos e conservadores. ${ }^{1}$ 


\section{Referências}

ARRUDA, N. et al. Discriminação entre estádios de maturação e tipos de processamento de pós-colheita de cafés arábica por microextração em fase sólida e análise de componentes principais. Quimica Nova, v. 34, n. 5, p. 819-824, 2011.

BEZERRA, C. M.; MINAYO, M. C. S.; CONSTANTINO, P. Estresse ocupacional em mulheres policiais. Ciência \& Saúde Coletiva, v. 18, n. 3, p. 657-666, 2013.

BIDERMAN, C.; GUIMARÁES, N. A. Na antessala da discriminação: o preço dos atributos de sexo e cor no Brasil (1989-1999). Revista Estudos Feministas, v. 12, n. 2, p. 177-200, 2004.

BORGES, A. F. et al. Contribuiçóes do diálogo entre o realismo crítico e o construcionismo social para os estudos organizacionais. Cadernos EBAPE. BR, v. 14, n. 2, p. 391-405, 2016.

BRAZ, C. Entre sobreviventes e bichas dos tempos dourados - memória, homossexualidade e sociabilidade na cidade de Goiânia, Brasil. Cadernos Pagu, n. 45, p. 503-525, 2015.

CACCIAMALI, M. C.; HIRATA, G. I. A influência da raça e do gênero nas oportunidades de obtenção de renda - uma análise da discriminação em mercados de trabalho distintos: Bahia e São Paulo. Estudos Econômicos (São Paulo), v. 35, n. 4, p. 767-795, 2005.

CAMBOTA, J. N.; PONTES, P. A. Desigualdade de rendimentos por Gênero Intra-ocupaçóes no Brasil, em 2004. Revista de Economia Contemporânea, v. 11, n. 2, p. 331-350, 2007.

CARVALHO, A. M.; TANURE, B.; ANDRADE, J. Executivas: carreira, maternidade, amores e preconceitos. RAE eletrônica, v. 9, n. 1, 2010.

CASTELAR, M. et al. Brinquedos e brincar na vida de mulheres educadoras. Psicologia Escolar e Educacional, v. 19, n. 3, p. 595-602, 2015.

CECHIM, P. L.; SELLI, L. Mulheres com HIV/AIDS: fragmentos de sua face oculta. Revista Brasileira de Enfermagem, v. 60, n. 2, p. 145-149, 2007.

CHIES, P. V. Identidade de gênero e identidade profissional no campo de trabalho. Revista Estudos Feministas, v. 18, n. 2, p. 507-528, 2010.

CLOSS, L. Q.; OLIVEIRA, S. R. História de vida e trajetórias profissionais: estudo com executivos brasileiros. Revista de Administração Contemporânea, v. 19, n. 4, p. 525-543, 2015.

COELHO, A. P. F. et al. Mulher-guerreira, mulher-homem: reconhecimento do trabalho e seus sentidos na percepção de mulheres recicladoras. Texto \& Contexto - Enfermagem, v. 25, n. 2, 2016.

CORTEZ, P. A. et al. A saúde docente no trabalho: apontamentos a partir da literatura recente. Cadernos Saúde Coletiva, v. 25, n. 1, p. 113-122, 2017.

; et al. Suicídio no trabalho: um estudo de revisão da literatura brasileira em psicologia. Revista Psicologia Organizaçôes e Trabalho, v. 19, n. 1, p. 523-531, 2019. 
; SOUZA, M. V. R. Menos profissionais, mais sujeitos: formação para a educação popular no Sistema Único de Saúde (SUS). Revista de Educação Popular, v. 16, n. 2, p. 27-37, 2017. ; OLIVEIRA, L. F. A. Princípios de uma política alternativa aos manicômios judiciais. Saúde e Sociedade, v. 27, p. 1206-1217, 2018.

; VEIGA, H. M. Desenvolvimento de bem-estar no trabalho e proatividade como estratégia de prevenção de intenção de rotatividade entre docentes de rede pública de ensino. In: SILVA, C. R. M. S (Org.). Administração, Empreendedorismo e Inovação - Volume 3. 1. ed. Ponta Grossa, Atena, 2019. p. 52-61.

.; ZERBINI, T.; VEIGA, H. M. S. Práticas. Work context and Burnout: confirmation of moderators from meta-analysis evidence. Revista Psicologia Organizaçôes e Trabalho, v. 19, n. 4, p. 755-761, 2019a.

.; ZERBINI, T.; VEIGA, H. M. S. Práticas humanizadas de gestão de pessoas e organização do trabalho: para além do positivismo e do dataísmo. Trabalho, Educação e Saúde, v. 17, n. 3, p. 1-23. 2019 b.

FERNANDES, G. A. D. E. A. L. Brazilian female labor market: racial-skin color discrimination and inefficiency. Economia Aplicada, v. 19, n. 2, p. 241-259, 2015.

FERREIRA, R. C. M.; FIGUEIREDO, M. A. C.; SOUZA, L. B. Trabalho, HIV/AIDS: enfrentamento e dificuldades relatadas por mulheres. Psicologia em Estudo, v. 16, n. 2, p. 259-267, 2011.

FLEURY, A. R. D.; TORRES, A. R. R. Análise psicossocial do preconceito contra homossexuais. Estudos de Psicologia (Campinas), v. 24, n. 4, p. 475-486, 2007.

FONSECA, R. M. G. S. A educação e o processo de inclusão: exclusão social da mulher: uma questão de gênero? Revista Brasileira de Enfermagem, v. 48, n. 1, p. 51-59, 1995.

FRANCO, T.; DRUCK, G.; SELIGMANN-SILVA, E. As novas relaçôes de trabalho, o desgaste mental do trabalhador e os transtornos mentais no trabalho precarizado. Revista Brasileira de Saúde Ocupacional, v. 35, n. 122, p. 229-248, 2010.

FREITAS, J. G. et al. Enfrentamentos experienciados por homens que vivem com HIV/Aids no ambiente de trabalho. Revista da Escola de Enfermagem da USP, v. 46, n. 3, p. 720-726, 2012.

GARCIA, A.; SOUZA, E. M. Sexualidade e trabalho: estudo sobre a discriminaçáo de homossexuais masculinos no setor bancário. Revista de Administração Pública, v. 44, n. 6, p. 1353-1377, 2010.

GIUBERTI, A. C.; MENEZES, N. Discriminação de rendimentos por gênero: uma comparação entre o Brasil e os Estados Unidos. Economia Aplicada, v. 9, n. 3, p. 369-384, 2005.

GÖÇMEN, İ.; YILMAZ, V. Exploring perceived discrimination among LGBT individuals in Turkey in education, employment, and health Care: Results of an online survey. Journal of Homosexuality, v. 64, n. 8, p. 1052-1068, 2017. 
GONTIJO, M. R.; MELO, M. C. O. L. Da inserção ao empoderamento: análise da trajetória de diretoras de instituiçóes privadas de ensino superior de Belo Horizonte. REAd. Revista Eletrônica de Administração (Porto Alegre), v. 23, n. spe, p. 126-157, 2017.

GUIMARÃES, N. A. Os desafios da eqüidade: reestruturação e desigualdades de gênero e raça no Brasil. Cadernos Pagu, n. 17-18, p. 237-266, 2002.

HIGA, F. C. Assédio sexual no trabalho e discriminação de gênero: duas faces da mesma moeda? Revista Direito GV, v. 12, n. 2, p. 484-515, 2016.

HOLLOWAY, I.; TODRES, L. The status of method: flexibility, consistency and coherence. Qualitative Research, v. 3, n. 3, p. 345-357, 2003.

HSIEH, H. F.; SHANNON, S. E. Three approaches to qualitative content analysis. Qualitative Health Research, v. 15, n. 9, p. 1277-1288, 2005.

IBRAHIM, I. From Ancient Greco-Roman Culture the Contemporary LGBTQ Community: The Transfer of Sex and Power Dynamics. Denison Journal of Religion, v. 15, n. 1, p. 1-7, 2016.

IRIGARAY, H. A. R.; FREITAS, M. E. Sexualidade e organizações: estudo sobre lésbicas no ambiente de trabalho. Organizaçóes \& Sociedade, v. 18, n. 59, p. 625-641, 2011.

IRIGARAY, H. A. R.; SARAIVA, L. A. S.; CARRIERI, A. P. Humor e discriminação por orientação sexual no ambiente organizacional. Revista de Administração Contemporânea, v. 14, n. 5, p. 890-906, 2010.

JACINTO, P. A. Diferenciais de salários por gênero na indústria avícola da região Sul do Brasil: uma análise com micro dados. Revista de Economia e Sociologia Rural, v. 43, n. 3, p. 529-555, 2005.

JESUS, E. S. et al. Preconceito na enfermagem: percepção de enfermeiros formados em diferentes décadas. Revista da Escola de Enfermagem da USP, v. 44, n. 1, p. 166-173, 2010.

JONATHAN, E. G. Mulheres empreendedoras: medos, conquistas e qualidade de vida. Psicologia em Estudo, v. 10, n. 3, p. 373-382, 2005.

KELLEHER, C. Minority stress and health: Implications for lesbian, gay, bisexual, transgender, and questioning (LGBTQ) young people. Counselling Psychology Quarterly, v. 22, n. 4, p. 373$379,2009$.

LIVRAMENTO, M. N.; HOR-MEYLL, L. F.; PESSÔA, L. A. G. P. Valores que motivam mulheres de baixa renda a comprar produtos de beleza. RAM. Revista de Administração Mackenzie, v. 14, n. 1, p. 44-74, 2013.

LLOREN, A.; PARINI, L. How LGBT-supportive workplace policies shape the experience of lesbian, gay men, and bisexual employees. Sexuality Research and Social Policy, v. 14, n. 3, p. 289-299, 2017. 
LOMBARDI, M. R. Engenheiras na construção civil: a feminização possível e a discriminação de gênero. Cadernos de Pesquisa, v. 47, n. 163, p. 122-146, 2017.

MADALOZZO, R. Occupational segregation and the gender wage gap in Brazil: an empirical analysis. Economia Aplicada, v. 14, n. 2, p. 147-168, 2010.

MARRI, I. G.; WAJNMAN, S. Esposas como principais provedoras de renda familiar. Revista Brasileira de Estudos de População, v. 24, n. 1, p. 19-35, 2007.

MELO, M. C. O. L. et al. Representações femininas na mídia de negócios brasileira. Organizaçôes \&. Sociedade, v. 11, n. 31, p. 103-118, 2004.

MIRANDA, A. P. M.; MAIA, B. Olhares, xingamentos e agressóes físicas: a presença e a (in) visibilidade de conflitos referentes às relaçôes de gênero em escolas públicas do Rio de Janeiro. Horizontes Antropológicos, v. 23, n. 49, p. 177-202, 2017.

MOLINIER, P. Cuidado, interseccionalidade e feminismo. Tempo Social, v. 26, n. 1, p. 17-33, 2014.

MONTEIRO, S.; CECCHETTO, F. Cor, gênero e classe: dinâmicas da discriminação entre jovens de grupos populares cariocas. Cadernos Pagu, n. 32, p. 301-329, 2009.

MOSCHKOVICH, M.; ALMEIDA, A. M. F. Desigualdades de gênero na carreira acadêmica no brasil. Dados, v. 58, n. 3, p. 749-789, 2015.

NICOLSON, P. Gender, power and organization: a psychological perspective on life at work. Routledge: London, 2015.

OLINTO, M. T. A.; OLINTO, B. A. Raça e desigualdade entre as mulheres: um exemplo no sul do Brasil. Cadernos de Saúde Pública, v. 16, n. 4, p. 1137-1142, 2000.

ORRILLO, J.; LOUREIRO, P. R. A. Managers effort and endogenous economic discrimination. Estudos Econômicos (São Paulo), v. 34, n. 3, p. 431-440, 2004.

OTINIANO-VERISSIMO, A. D. et al. Racial discrimination, gender discrimination, and substance abuse among Latina/os nationwide. Cultural Diversity and Ethnic Minority Psychology, v. 20, n. 1, p. 43-51, 2014.

PAIXÃO, M.; GOMES, F. Histórias das diferenças e das desigualdades revisitadas: notas sobre gênero, escravidão, raça e pós-emancipação. Revista Estudos Feministas, v. 16, n. 3, p. 949-969, 2008.

PAUTASSI, L. C. Há igualdade na desigualdade? Abrangência e limites das ações afirmativas. Sur Revista Internacional de Direitos Humanos, v. 4, n. 6, p. 70-93, 2007.

PEREIRA, H; COSTA, P. A. Modeling the impact of social discrimination on the physical and mental health of Portuguese gay, lesbian and bisexual people. Innovation: The European Journal of Social Science Research, v. 29, n. 2, p. 1-13, 2016. 
SANCHES, S.; GEBRIM, V. L. M. O trabalho da mulher e as negociações coletivas. Estudos Avançados, v. 17, n. 49, p. 99-116, 2003.

SANTOS, C. E.; TAKAHASHI, R. T. Resgatando a trajetória profissional do enfermeiro do sexo masculino: um enfoque fenomenológico. Revista Brasileira de Enfermagem, v. 53, n. 2, p. 183-191, 2000.

SANTOS, N. J. S. Mulher e negra: dupla vulnerabilidade às DST/HIV/Aids. Saúde e Sociedade, v. 25, n. 3, p. 602-618, 2016.

SANTOS, C. J. Crimes de preconceito e de discriminação. Editora Saraiva: São Paulo, 2017.

SILVA, F. F.; RIBEIRO, P. R. C. Trajetórias de mulheres na ciência: ser cientista e ser mulher. Ciência \& Educação (Bauru), v. 20, n. 2, p. 449-466, 2014.

SILVA, K. A. T.; CAPPELLE, M. C. A. Sentidos do trabalho apreendidos por meio de fatos marcantes na trajetória de mulheres prostitutas. RAM. Revista de Administração Mackenzie, v. 16, n. 6, p. 19-47, 2015.

SILVA, V. H. M. C.; FRANÇA, J. M. S.; PINHO, V. R. Capital humano e desigualdade salarial no Brasil: uma análise de decomposição para o período 1995-2014. Estudos Econômicos (São Paulo), v. 46, n. 3, p. 579-608, 2016.

SIQUEIRA, M. V. S. et al. Homofobia e violência moral no trabalho no Distrito Federal. Organizaçôes \& Sociedade, v. 16, n. 50, p. 447-461, 2009.

SMITH, A. P. O.; SANTOS, J. L. O. Corpos, identidades e violência: o gênero e os direitos humanos. Revista Direito e Práxis, v. 8, n. 2, p. 1083-1112, 2017.

SOUSA, P. J.; FERREIRA, L. O. C.; SÁ, J. B. Estudo descritivo da homofobia e vulnerabilidade ao HIV/Aids das travestis da Região Metropolitana do Recife, Brasil. Ciência \& Saúde Coletiva, v. 18, n. 8, p. 2239-2251, 2013.

SOUZA, E. M.; PEREIRA, S. J. N. (Re)produção do heterossexismo e da heteronormatividade nas relaçóes de trabalho: a discriminação de homossexuais por homossexuais. RAM. Revista de Administração Mackenzie, v. 14, n. 4, p. 76-105, 2013.

SOUZAS, R.; ALVARENGA, A. T. Direitos sexuais, direitos reprodutivos: concepçóes de mulheres negras e brancas sobre liberdade. Saúde e Sociedade, v. 16, n. 2, p. 125-132, 2007.

STRAUSS, A.; CORBIN, J. Grounded theory methodology. Handbook of Qualitative Research, v. 17 , p. 273-85, 1994.

THOMSON, S. B.; GRANDY, G. Stigmas, Work and Organizations. United Kingdom: Palgrave Macmillan, 2018.

TONELI, M. J. F.; PERUCCHI, J. Territorialidade homoerótica: apontamentos para os estudos de gênero. Psicologia \& Sociedade, v. 18, n. 3, p. 39-47, 2006. 
VERNIERS, C.; VALA, J. Justifying gender discrimination in the workplace: The mediating role of motherhood myths. PloS One, v. 13, n. 1, p. e0190657, 2018.

WERMELINGER, M.; MACHADO, M. H.; AMÂNCIO, A. Políticas de educação profissional: referências e perspectivas. Ensaio: Avaliação e Políticas Públicas em Educação, v. 15, n. 55, p. 207-222, 2007.

WHITTEMORE, R.; KNAFL, K. The integrative review: updated methodology. Journal of Advanced Nursing, v. 52, n. 5, p. 546-553, 2005.

WINTHER, J. M.; GOLGHER, A. B. Uma investigação sobre a aplicação de bônus adicional como política de ação afirmativa na Universidade Federal de Minas Gerais (UFMG). Revista Brasileira de Estudos de População, v. 27, n. 2, p. 333-359, 2010.

WINTER, S. et al. Transgender people: health at the margins of society. Lancet, v. 388, n. 10.042, p. 390-400, 2016.

WOULFE, J. M.; GOODMAN, L. A. Identity abuse as a tactic of violence in LGBTQ communities: Initial validation of the identity abuse measure. Journal of interpersonal violence, p. 1-21, 2018.

\section{Nota}

1 P. A. Cortez e M. V. R. de Souza participaram da formulação e execução do projeto de pesquisa, redação e revisão do manuscrito. A. P. Salvador e L. F. A. Oliveira participaram da execuçáo do projeto de pesquisa, redação e revisão do manuscrito. 


\section{Abstract}

Sexism, misogyny, and LGBTQphobia:

challenges to promote inclusive work practices

in Brazil

Violent practices permeate different social contexts, including work spaces. In this sense, it is essential to promote inclusive work, as the practices of domination at work relegate to marginalization different social actors, including women and LGBTQs, causing harm to the psychosocial health of these groups. In order to contribute to this aspect, it was proposed a critical review of the productions on practices of violence and domination in the context of work aimed at the female population and LGBTQs, in order to identify the challenges in the proposition of inclusive work in Brazil. The descriptors "work" and "prejudice" or "discrimination" were used in a literature search between 1995 and 2017 in the Scielo database, which allowed the identification of 54 studies included in this review. The results pointed by the reviewed studies found violence with women and LGBTQs in the various work contexts, practiced by bosses, colleagues, clients, among other subjects. Thus, it is a challenge for the proposition of inclusive work to implement educational and assistance interventions, supported by laws and public policies that promote respect and equity to diversity as a keynote in Brazilian social organizations and work contexts.

> Keywords: employment discrimination; working women; homophobia; gender identity; affirmative action. 